\title{
LA INTERPRETACIÓN DE LA COMPETENCIA DEL ESTADO SOBRE LAS BASES Y LA COORDINACIÓN DE LA PLANIFICACIÓN GENERAL DE LA ACTIVIDAD ECONÓMICA (ART. 149.1.13 DE LA CONSTITUCIÓN)
}

\author{
POR \\ MANUEL CARRASCO DURÁN \\ Profesor Titular de Derecho Constitucional \\ Universidad de Sevilla
}

\section{PLANTEAMIENTO}

La actividad económica, contemplada como objeto de la distribución de competencias entre el ente político-territorial central y los entes políticoterritoriales autónomos, plantea una problemática muy particular en los Estados políticamente descentralizados. Por una parte, la aspiración por controlar y dirigir la ordenación del desarrollo de las actividades económicas que tienen lugar en el territorio y del aprovechamiento de los recursos con utilidad económica es, junto con la preservación de las peculiaridades culturales 
y lingüísticas, uno de los elementos fundamentales que explican las facultades de autogobierno de los entes político-territoriales autónomos en dichos Estados. Así, por ejemplo, la actividad económica es uno de los principales ámbitos sobre los que recaen las competencias de los $L$ nderen Alemania y de los Estados que integran los Estados Unidos

En España, la lectura de la Constitución y de los Estatutos de Autonomía muestra también una acusada tendencia a la descentralización de la ordenación pública de las actividades económicas. Así, la Constitución sólo ha reservado al Estado competencias sobre algunas actividades económicas que tienen una repercusión general, en cuanto condicionan el desarrollo del conjunto de la actividad económica (ordenación del crédito, banca y seguros, régimen minero y energético, transportes supracomunitarios), y sobre el comercio exterior y la pesca marítima, debido a la dimensión internacional de estas actividades, y aun así, en los casos de la ordenación del crédito, banca y seguros y del régimen minero y energético sus facultades se limitan a establecer las bases de las mismas. Y, junto a ello, el Estado tiene también una competencia sobre las bases y la coordinación de la planificación general de la actividad económica que abarca toda actividad de esta clase, pero que, al mismo tiempo, limita el alcance de la intervención del Estado al marco de lo que pueda entenderse como bases, coordinación y planificación general. En contraste, la ordenación de las restantes actividades económicas ha sido asumida por las Comunidades Autónomas en sus Estatutos con el carácter de competencia exclusiva (es el caso del turismo, la pesca en aguas interiores, marisqueo, acuicultura, pesca fluvial y lacustre, artesanía y casinos, juegos y apuestas, excepto las Apuestas Mutuas Deportivo Benéficas) o de competencia exclusiva de acuerdo con las bases y la ordenación de la actividad económica general y la política monetaria del Estado y en los términos de lo dispuesto en los artículos 38, 131 y en las reglas de los apartados 11 y 13 del artículo 149 de la Constitución (como ocurre con la industria, salvo determinadas excepciones contempladas en los Estatutos de Autonomía, la agricultura, la ganadería, el comercio interior y las instituciones de crédito corporativo, público y territorial y Cajas de Ahorro), y, además, en las actividades objeto de competencias del Estado sobre las bases, las Comunidades Autónomas han asumido las facultades de desarrollo legislativo y ejecución que complementan dicha competencia estatal (ordenación del crédito, banca y seguros, régimen minero y energético, ordenación del sector pesquero, en la que, pese a que el artículo 149.1.19ª no ha reservado al Estado ninguna competencia en concreto, las Comunidades Autónomas han asumido solamente el desarrollo legislativo y ejecución).

Sin embargo, es también notorio que el reparto de poder sobre las actividades económicas expresado en las normas fundamentales de la ordenación político-territorial de los Estados descentralizados viene sufriendo una fuerte tendencia a la centralización, esto es, a la acumulación en el ente polí- 
tico-territorial central de la ordenación de las actividades económicas o, al menos, de la ordenación de todos los aspectos centrales del desarrollo de aquéllas, mientras que a los Entes descentralizados se les reservan funciones que son, fundamentalmente, de ejecución de la normativa estatal. Esta tendencia a la centralización de la ordenación de la actividad económica viene provocada por factores tales como la dimensión supranacional que han adquirido tales actividades, la necesidad del Estado de hacer frente a los compromisos contraídos en organizaciones internacionales que se ocupan, solamente o preferentemente, de armonizar el ejercicio de las actividades económicas en el marco internacional (principalmente, aunque no solamente, la Unión Europea) y el hecho de que la actividad económica sólo pueda desarrollarse adecuadamente en un marco de coherencia, seguridad y estabilidad en su regulación jurídica que, para una línea doctrinal, sólo el Estado podría garantizar a escala nacional.

Esta tendencia a la centralización de la ordenación de las actividades económicas se ha visto recogida en los Estados federales de nuestro entorno a través de reformas constitucionales (como ha ocurrido en Alemania y Suiza, principalmente), de una aplicación amplia de las facultades de la Federación para la ordenación de las actividades económicas y de una interpretación jurisprudencial generosa de los términos en los que se expresan las cláusulas de la Constitución federal que enuncian las competencias de la Federación sobre las actividades económicas, lo que ha llevado a algunos autores a señalar que la actividad económica es el ámbito donde se registran en los Estados federales las mayores desviaciones entre lo previsto en la Constitución y la práctica del ejercicio de las funciones públicas por parte de la Federación y de los entes político-territoriales que operan en el nivel descentralizado ${ }^{1}$.

${ }^{1}$ GIANNINI, M. S.; Diritto pubblico dell? ecolthAuilino, Bolonia, 1985, pág. 313, BOIS, P.; "L'organisation de I'administration. Du concentré à l'excentrique», en AA. VV.; Rechts als Prozess und Gef ge, Festschrift f $r$ Hans Huber zum 80Becmurtstag, 1981, págs. 635 y s., y, en el mismo sentido, MAHON, P.; La d centralisation admin-istrati ve: tude de droit publique fran ais, allemandDroz, Giniebra, 1985, pág. 196, VERGOTTINI, G. de; "Regiones y Estado en la dinámica institucional. Consideraciones comparadas", RVAP , 14 (1986), 14. Para el caso de España, se pronuncian en el mismo sentido CORCUERA ATIENZA, F. J.; "Participación de las Administraciones autonómicas y locales en la economía», en AA. VV. (coords. F. J. Corcuera Atienza y M. Á. García Herrera); Constituci n $y$ econom a en Espa a: Gobierno de la econom a $y$ Administraciones P bl i całnstituto Vasco de Administración Pública, Oñati, 1988, pág. 51, y JIMÉNEZ-BLANCO CARRILLO DE ALBORNOZ, A.; "La distribución de competencias económicas entre el Estado y las Comunidades Autónomas", en AA. VV. (dir. S. Martín-Retortillo Baquer); Pasado, presente y futuro de las Comunidades Aut nom Económicos, Madrid, 1989, pág. 466, y también págs. 413 y s. y 461 y s. 
En nuestro país, la recepción de la tendencia que acabamos de describir se ha llevado a cabo mediante la utilización por parte del Estado de su competencia sobre las bases y la coordinación de la planificación general de la actividad económica con vistas a llevar a cabo, a partir de ella, una ordenación extensa y uniforme de todas las actividades económicas que tienen lugar en el ámbito estatal y mediante la sanción que esta práctica ha recibido por parte de la jurisprudencia del Tribunal Constitucional. En concreto, para percibir la peculiaridad de la interpretación que el Tribunal Constitucional viene manteniendo acerca del ámbito de la competencia estatal sobre las bases y la planificación general de la actividad económica hay que partir del hecho de que la Constitución, con esta competencia, ha asignado al Estado, ciertamente, una facultad para intervenir genéricamente en la ordenación de toda la actividad económica, pero, sin embargo, también ha sido la Constitución consciente del amplísimo potencial que tiene una competencia como ésta y, en vista de ello, ha intentado limitar las facultades que aquélla atribuye al Estado mediante cuatro precisiones. En primer lugar, las facultades derivadas de esta competencia sólo se pueden ejercer sobre la actividad económica, lo cual deja fuera otras actividades y elementos que, aunque tengan repercusión en el ejercicio de las actividades económicas, no pueden ser catalogados propiamente, por su naturaleza, como "actividad económica»; en segundo lugar, la competencia no permite al Estado llevar a cabo cualquier tipo de ordenación de la actividad económica, sino solamente la planificación de la misma, lo que circunscribe el ámbito de la competencia a un tipo de actuación pública que, por sus características, pueda calificarse de "planificación»; en tercer lugar, la Constitución requiere que la planificación sea "general»; y, finalmente, el Estado no puede ejercer cualquier tipo de potestad sobre la planificación general de la actividad económica, sino que, por el contrario, sólo puede determinar dicha planificación en el marco de "bases" y llevar a cabo la coordinación de la misma. Pues bien, lo característico de la interpretación del Tribunal Constitucional acerca de esta competencia es que ha utilizado estas cuatro precisiones que la Constitución emplea para delimitar, y, con ello, también para limitar el ámbito de actuación conferido al Estado por esta competencia, paradójicamente, en un sentido contrario, es decir, para ampliar el ámbito de la competencia genérica del Estado sobre la ordenación de la actividad económica hasta dejar el sentido de aquélla en la mayor indeterminación².

\footnotetext{
${ }^{2}$ En la doctrina, pueden destacarse las consideraciones sobre la interpretación de la competencia acerca de las bases y la coordinación de la planificación general de la actividad económica llevadas a cabo por ALBERTí ROVIRA, E.; Autonom a pol tica y unidad econ mica (las dimensiones constitucional y europea de la libre circulaci n y de
} 


\section{LA INTERPRETACIÓN DEL CONCEPTO «ACTIVIDAD ECONÓMICA»: LA COMPETENCIA SOBRE LAS BASES Y LA COORDINACIÓN DE LA PLANI- FICACIÓN GENERAL DE LA ACTIVIDAD ECONÓMICA COMO COMPETEN- CIA HORIZONTAL O TRANSVERSAL}

Comenzando por la interpretación acerca de cuál es la actividad económica sobre la que puede ejercerse esta competencia, el Tribunal Constitucional ha admitido con naturalidad que las normas y actuaciones del Estado que toman como fundamento la competencia del artículo 149.1.13a de la Constitución pueden estar dirigidas no sólo a la ordenación de la actividad económica en general, sino también a la ordenación parti-

unidad de mercadolivitas, Institut d'Estudis Autonòmics, Madrid, 1995; BALZA AGUILERA, J.; "Trayectoria en la interpretación del artículo 149.1.13 CE», en AA. VV. (dir. A. Pérez Calvo); Normativa b sica en el ordenamiento jur dico estAbAB,IMadrid, 1990, págs. 133 y ss.; CALONGE VELÁZQUEZ, A.; Autonom a pol tica y unidad de mer cado en la Constituci n espa ola de 1978ecretariado de Publicaciones de la Universidad de Valladolid, Valladolid, 1988; CORCUERA ATIENZA, J.; ob. cit., págs. 47 y ss.; GARCÍA TORRES, J.; "Máximas de interpretación sobre el artículo 149.1.13 CE en la reciente Jurisprudencia Constitucional», en Normativa b sica enob. cit., págs. 138 y ss.; GÓMEZ-FERRER MORANT, R.; "Bases y ordenación general de la economía», en Normativa b sica en. o.b. cit., págs. 121 y ss.; JIMÉNEZ-BLANCO CARRILLO DE ALBORNOZ, A.; "La distribución de competencias económicas entre el Estado y las Comunidades Autónomas", en AA. VV. (dir. S. Martín Retortillo); Pasado, presente y futuro de las Comunidades Aut nomdEE, Madrid, 1989, págs. 391 y ss.; LASAGABASTER HERRARTE, I.; «Planificación y ordenación de la economía: títulos competenciales y problemas específicos", en Estudios sobre el Estatuto de Autonom a del Pa s Vasco,t. II, IVAP, Oñati, 1991, págs. 687 y ss.; MALARET I GARCÍA; «Aplicación de las previsiones constitucionales y estatutarias en materia de competencias económicas", en AA. VV. (coord. S. Martín-Retortillo Baquer); Estudios sobre la Constituci n Espa ola. Homenaje al Profesor Eduardo Garc a de tEdt Givitas, Madrid, 1991, págs. 4.056 y ss.; PAREJO ALFONSO, L.; "Situación actual y perspectiva de evolución del Estado autonómico. Una reflexión crítica: el papel central de la política económica", $P E E$, 35 (1988), 377 y ss.; PULIDO QUECEDO, M.; "La jurisprudencia del Tribunal Constitucional en materia de competencias económicas", RVAP, 18 (1987); RODRíGUEZARANA MUÑOZ, J.; "Competencias económicas, Estado y Comunidades Autónomas", en Estudios de derecho auton mAlontecorvo, Madrid, 1997, págs. 121 y ss.; SAINZ MORENO, F.; «El principio de unidad del orden económico y su aplicación por la jurisprudencia constitucional", en Pasado, presente yob. çit., págs. 231 y ss.; TENA PIAZUELO, V.; La unidad de mercado en el Estado auton mEsouela Libre Editorial, Madrid, 1997; y TORNOS I MAS, J.; «El proceso de distribución de las competencias económicas y la necesaria unidad de la política económica", REDA, 29 (1981), 319 y ss., y 
cular de cada uno de los sectores de la actividad económica y, concretando más, incluso a la ordenación de manifestaciones singulares de la actividad económica que, en su especificidad, no puede considerarse siquiera que engloben totalmente alguno de los sectores en los que típicamente se suele dividir la actividad económica a efectos de detallar el contenido de aquélla. Así, por poner sólo dos ejemplos, la STC 29/1986, FJ 4, señala que "corresponde al Estado la ordenación de la actuación económica general, lo cual ha de interpretarse como ordenación de la actuación económica de todos los sectores y del propio Estado con relación a ellos, es decir, de la propia intervención del Estado en materia económica", y la STC 86/1989, FJ 3, manifiesta que la competencia del artículo 149.1.13 ${ }^{\text {a }}$ de la Constitución atribuye al Estado la facultad de intervenir "en todo el ámbito que pueda alcanzar trascendencia económica ${ }^{3}$ ". En la práctica, el Estado ha utilizado la competencia del artículo 149.1.13a de la Constitución para llevar a cabo la ordenación básica del ejercicio de cada una de las actividades económicas consideradas desde una perspectiva sectorial y singular.

Esto ha convertido la competencia del artículo 149.1.13 a de la Constitución en uno de los ejemplos más característicos de lo que se viene denominando como competencia "horizontal" o "transversal», esto es, en una competencia de ámbito material genérico y de titularidad estatal que atraviesa un gran número de materias sectoriales objeto de competencias de las Comunidades Autónomas. De hecho, la competencia del artículo 149.1.13 ${ }^{\mathrm{a}}$ de la Constitución puede definirse de una manera más gráfica como competencia "plurisectorial», ya que, a partir de ella, el Estado puede intervenir en la ordenación de todos los sectores de la actividad económica, incluyendo aquéllos sobre los cuales las Comunidades Autónomas tienen reconocidas competencias. Como quiera que, además, muchas de las competencias de las Comunidades Autónomas sobre las actividades económicas vienen reconocidas en sus Estatutos de Autonomía con el carácter de exclusivas o el de exclusivas "de acuerdo con las bases y la ordenación de la actividad económica general y la política económica del Estado... en los términos de lo dispuesto en los artículos 38, 131 y en los números 11 y 13 del aparado 1 del artículo 149 de la Constitución» (art. 12.1 del Estatuto de Autonomía de Cataluña y, en el

${ }^{3}$ Esta interpretación de la competencia sobre las bases y coordinación de la planificación general de la actividad económica fue admitida ya por la STC 76/1983. El carácter singularizado de la delimitación del objeto de las normas relativas a la actividad económica que pueden encuadrarse en la competencia del artículo $149.1 .13^{\mathrm{a}}$ de la Constitución queda claro en la normativa sobre las medidas de apoyo y fomento de las actividades económicas fundamentadas en ella. 
mismo sentido, el art. 18.1 del Estatuto de Autonomía de Andalucía, cuyos modelos siguieron todos los demás, si bien, como excepción, el Estatuto de Autonomía del País Vasco no contiene una cláusula similar), esta interpretación del ámbito material de la competencia del artículo 149.1.13a de la Constitución da como resultado un solapamiento de esta competencia con las competencias autonómicas que revisten la naturaleza que se acaba de indicar.

Pero, además, en virtud de interpretaciones finalistas del objeto material "actividades económicas", la jurisprudencia del Tribunal Constitucional ha permitido al Estado regular, tomando como base la competencia del artículo 149.1.13aㅡ de la Constitución, determinados aspectos de materias que, aun teniendo repercusión en la actividad económica, no pueden ser consideradas en sí, por su naturaleza, como actividad económica, como es el caso de la vivienda (STC 152/1988, FJ 4, teniendo en cuenta que la materia vivienda se refiere fundamentalmente a la política pública dirigida a satisfacer la demanda de vivienda de los ciudadanos, mientras que los aspectos económicos entremezclados en las políticas de vivienda ocupan, en este marco, un lugar secundario) o el urbanismo (STC $61 / 1997$, FJ 36, y 124/2003, FJ 3), y de recursos e infraestructuras que constituyen elementos necesarios para que las actividades económicas puedan llevarse a cabo pero que, en sí, tampoco son actividades económicas y que son, incluso, objeto de otras competencias específicas del propio Estado [SSTC 227/1988, FJ 20.b) y d), que enmarcan en la competencia del artículo 149.1.13 de la Constitución las disposiciones de la planificación hidráulica relativas a la protección y aprovechamiento de los recursos hidráulicos en materia de prioridad y compatibilidad de usos, medio ambiente, ordenación del territorio, agricultura y montes, infraestructura, aprovechamientos energéticos, protección civil, etc., y 65/1998, FJ 7, sobre principios generales del sistema de carreteras] $]^{4}$. La interpretación que conduce a este tipo de resultados deja a un lado la naturaleza objetiva de los elementos afectados por la normativa objeto de examen y sigue, en cambio, un criterio finalista que es patente en la STC 225/1993, FJ 3.D), relativa a la regulación de los horarios comerciales, para lo cual el elemento de contraste a la hora de determinar el encuadramiento material de determinadas actuaciones debe ser "el examen detenido de la finalidad de la norma estatal de acuerdo "a su objetivo predominante" (STC 13/1989), así como la necesaria correspondencia de esa medida con los intereses y fines generales que

\footnotetext{
${ }^{4}$ Sobre la interpretación de las materias competenciales, vid.VIVER I PI-SUNYER, C.; Materias competenciales y Tribunal Consti Ariélo Barcelona, 1988, especial-
} 
justifican la intervención del Estado para la ordenación de la actividad económica general ${ }^{5}$ ".

De esta manera, el Estado ha encontrado en la competencia del artículo 149.1.13 de la Constitución el fundamento para ordenar jurídicamente cualquier actividad económica, sea cual sea el grado de especificidad del objeto de dicha ordenación, y cualquier actividad o elemento que pueda tener repercusión en el ejercicio de las actividades económicas, aunque, por su naturaleza, no tenga en sí el carácter de actividad económica.

\section{LA DESNATURALIZACIÓN DEL CONCEPTO DE «PLANIFICACIÓN GENERAL»}

Pasando al examen de la interpretación del concepto de planificación, nos encontramos con una paradoja. Las intervenciones que tuvieron lugar en los debates constituyentes al hilo de este tema partieron del concepto clásico de planificación central del conjunto de la economía, al estilo de los antiguos Planes de Desarrollo, y se centraron en discutir si la planificación, así entendida, debía o no estar mencionada en la Constitución y, sobre todo, si la planificación habría de seguir el modelo francés y ser, por tanto, obligatoria para el sector público e indicativa para el sector privado, o si sería admisible una planificación que siguiera el modelo soviéti-

${ }^{5}$ No obstante, estos argumentos producen un cierto desconcierto cuando en una misma materia se comparan sentencias que parten de criterios finalistas a la hora de determinar el encuadramiento material de las actuaciones que examinan y otras que siguen criterios objetivos, que examinan prioritariamente la naturaleza del sector de la realidad al que se refiere la materia correspondiente, según el significado objetivo de sus términos. Así, por ejemplo, mientras las STC 106/1987, FJ 4, entendió que la concesión de licencias de doblaje de películas extranjeras, unida a la imposición de cuotas de distribución en el mercado cinematográfico, "tiene una finalidad económica", que la sentencia cifra en la protección de la industria cinematográfica española, y que, en esta actuación "los aspectos económicos... se entrecruzan e incluso predominan sobre los específicamente culturales", la STC 143/1985, FJ 13, señaló, en cambio, que la regulación de las cuotas de pantalla y distribución cinematográfica y de las condiciones de obtención de licencias de doblaje de películas extranjeras debe encuadrarse en la materia de "espectáculos", sin que dicha calificación pueda ser desvirtuada por la "eventual incidencia lateral» que las competencias relativas al comercio exterior (art. 149.1.10 de la Constitución) y a las bases y coordinación de la planificación general de la actividad económica pudieran tener sobre la actividad cinematográfica. Ésta, sin embargo, es sólo una muestra de los vaivenes que ha sufrido la jurisprudencia al encuadrar materialmente en títulos competenciales actuaciones relativas a la actividad cinematográfica. 
co y que fuera obligatoria para todos los sectores de la economía. Esta planificación, sin embargo, no existe ya ni en nuestro país ni en los demás países de nuestro entorno geográfico, político y económico, y, por lo tanto, interpretándola como la entendían mayoritariamente quienes discutieron y elaboraron la Constitución, tendríamos una competencia vacía por falta de una materia sobre la cual ejercerla. Como las normas deben interpretarse de acuerdo con la realidad del tiempo en el que deben ser aplicadas, esto aboca a la necesidad de dejar a un lado el criterio histórico de interpretación y sostener una interpretación funcional según la cual sería un ejercicio de planificación toda norma en la que se plasme una voluntad de dirigir las actividades económicas al logro de determinados fines tras una evaluación genérica de los problemas, carencias y necesidades planteados en el desarrollo de dichas actividades y de las medidas que deben adoptarse desde los poderes públicos para intentar superar dichas disfunciones. Es decir, toda norma que obedezca a los fines característicos de la planificación económica, independientemente de su forma o su ámbito material.

El hecho es que el Tribunal Constitucional, en la práctica, ha venido incluyendo en el concepto de planificación cualquier tipo de ordenación de la actividad económica en la que haya advertido una incidencia importante en la economía o una conexión con los objetivos de la política económica marcados por el propio Estado. Pero, además, ha aceptado dentro de esta competencia multitud de normas y actuaciones en las que falta la evaluación general de problemas y necesidades y de objetivos y medidas para alcanzarlos que caracteriza a la planificación, como intento de introducir racionalidad en la ordenación del desarrollo de las actividades económicas, bien porque se trate de normas que se refieren a modalidades muy singulares del ejercicio de un sector de la actividad económica que no tienen la capacidad de condicionar el desarrollo global del sector de la actividad al que pertenecen, bien porque se trate de normas en las que la falta de determinación de los objetivos que se pretenden con ellas o en los que la determinación de tales objetivos se cubren con referencias muy genéricas de las que es poco lo que se puede derivar en cuanto a concreción de su finalidad ${ }^{6}$, bien, finalmente, porque se trate de normas de carácter

${ }^{6}$ Como ejemplo, la STC 213/1994, FJ 7, infiere el carácter básico de unas medidas tomando como base la alusión de la Exposición de Motivos de la norma que las regulaba a fines tan genéricos como "la mejora de las condiciones de vida, trabajo y producción de la población agraria", que podrían haber sido deducidos de cualquier norma relativa a actividades conectadas con la agricultura, y la STC 175/2003, FJ 7, extrae los fines que justifican determinadas subvenciones del Estado de determinados objetivos genéricos (la modernización, la promoción industrial y tecnológica, la innovación y la 
coyuntural, en las que falta la vocación de permanencia y de ordenación de aspectos estructurales del ejercicio de las actividades económicas que caracteriza a la actuación de planificación.

El resultado es que el concepto de planificación ha quedado difuminado hasta el extremo de que, desde los criterios examinados, cualquier ordenación de la actividad económica puede enmarcarse en él, independientemente de su naturaleza, lo que ha expandido de forma ostensible el ámbito material real de la competencia del artículo 149.1.13 $3^{\mathrm{a}}$ de la Constitución. Así, no puede extrañar que el propio Tribunal Constitucional, cuando tiene que referirse a la competencia del artículo 149.1.13를 de la Constitución, olvide en algunas ocasiones el término "planificación" y se refiera a esta competencia con la denominación de "ordenación general de la economía" [SSTC 1/1982, FJ 5, 152/1988, FJ 2, 186/1988, FJ 2, 14/1989, FJ 3, 146/1992, FJ 2, 21/1999, FJ 5, 128/1999, FJ 7.a), y 95/2001, FJ 2], «dirección de la actividad económica general», "dirección general de la economía» o "dirección económica de los diferentes sectores productivos" [SSTC 95/1986, FJ 4, 29/1994, FJ 4.A), y 175/2003, FJ 16], "bases de la ordenación del sector» (STC 95/1986, FJ 2), "programación y ordenación de un sector específico" con la que el Estado "puede determinar las bases a que ha de atenerse la Generalidad en el ejercicio de sus propias competencias" (STC 80/1985, FJ 1), "medidas de ordenación básica del sector agrícola (STC 96/1986, FJ 3), "normas básicas de ordenación del sector industrial» o "establecimiento de las normas de ordenación económica que se proyectan sobre el sector industrial» (STC $175 / 2003$, FFJJ 7 y 9) u otras semejantes. De hecho, una de las principales finalidades con la que el Estado suele utilizar la competencia del artículo 149.1.13a de la Constitución viene a ser la de llevar a cabo la ordenación básica de sectores de la actividad económica con respecto a los cuales la Constitución no le reconoce a aquél competencia específica alguna y en los

mejora de la competitividad) que ni siquiera son mencionados en las Órdenes Ministeriales que regulan dichas subvenciones, sino en la Ley 2/1992, de Industria. De igual modo, la STC 225/1993, pese a discrepar de la valoración de la trascendencia de la regulación de los horarios comerciales para la conformación del régimen de ejercicio de las actividades económicas que lleva a cabo el representante del Estado en el recurso de inconstitucionalidad que resuelve, termina asumiendo de manera acrítica los fines expresados en la Exposición de Motivos por el Real Decreto-ley 2/1985 y, de esta forma, admite la liberalización total de los horarios comerciales por parte del Estado, con lo que, como señala Tornos Mas, emplea un razonamiento circular que actúa "expandiendo el fin de la norma aprobada por el Estado según la definición que de la misma hace el propio Estado". Vid.TORNOS I MAS, J.; "Libertad de horarios comerciales y marco 
que, por el contrario, las Comunidades Autónomas han asumido competencias que sus Estatutos de Autonomía califican como "exclusivas», bien a secas, bien en el marco de la ordenación general de la economía.

En cuanto al adjetivo "general», éste no ha suscitado particular reflexión en la jurisprudencia constitucional, si bien pueden entresacarse de ella dos datos que resultan interesantes a los fines de nuestra exposición. Por un lado, esta palabra ha contribuido a apoyar la interpretación extensa por parte del Estado de su ámbito de intervención en la ordenación de las actividades académicas en aquellos casos en los que el significado de la regla competencial del artículo 149.1.13 ${ }^{\mathrm{a}}$ de la Constitución ha sido identificado con la expresión "ordenación general de la actividad académica» u otras similares. Por otro lado, hay que recalcar que, mientras en la interpretación del artículo 131.2 de la Constitución el adjetivo "general» adherido en dicho artículo a la expresión "actividad económica" ha sido utilizado para limitar las posibilidades de intervención de las Comunidades Autónomas en la elaboración de la planificación económica a los planes que tengan como objeto el conjunto de la actividad económica (SSTC 29/1986, FJ 3, 186/1988, FJ 7, 227/1988, FJ 20, 103/1989, FJ 5, 45/1991, FJ 4, entre otras), con lo que, en la práctica, se ha venido a hacer imposible dicha participación, ya que este tipo de planificación global de la economía no existe hoy en día, cuando, por el contrario, se ha tratado de interpretar la regla del artículo 149.1.13a de la Constitución la mención de la palabra "general» no ha sido óbice para que el Tribunal Constitucional reconozca la posibilidad de que el Estado lleve a cabo desde dicha regla competencial cualquier planificación de tipo sectorial de las actividades económicas. Ciertamente, en el artículo 131.2 el término general se refiere directamente a la actividad económica, mientras que en el 149.1.13a el mismo término se ha adherido a la palabra "planificación», pero de la lectura de ambos artículos no se deduce que deba darse al cambio de posición de dicho adjetivo en la frase más trascendencia que la de una simple incidencia gramatical ${ }^{7}$.

\section{LA OMISIÓN DE LAS EXIGENCIAS FORMALES DEL CONCEPTO DE BASES}

La jurisprudencia sobre la competencia del artículo 149.1.13a de la Constitución muestra uno de los ejemplos más extremos de la indetermi-

7 Vid.BASSOLS COMA, M.; "La planificación económica», en AA. VV. (coord. F. Garrido Falla); El modelo econ mico en la Constituci n espat.ollalEE, Madrid, 1981, p. 439. 
nación e incertidumbre en la que siempre se mueve la interpretación del significado de lo básico.

Comenzando por el examen de la interpretación de los elementos formales de las bases en relación con la competencia del artículo 149.1.13 de la Constitución, el dato más Ilamativo es que la posibilidad de regular las bases mediante normas reglamentarias, que la STC 69/1988, asumida generalmente como la sentencia que establece las líneas fundamentales para la interpretación del concepto de bases, recoge como excepcional, ha sido acogida de forma tan amplia por la jurisprudencia que, en ocasiones, se tiene la impresión de que, cuando se trata de esta competencia, la excepción, esto es, la admisión de la regulación de las bases mediante reglamento, se ha convertido en la regla.

Vistas así las cosas, el Tribunal Constitucional se ha centrado en las SSTC 213/1994, FJ 10, y 235/1999, FJ 15, en exigir, al menos, que las normas que desarrollen la competencia del artículo 149.1.13a de la Constitución no sean Órdenes Ministeriales, para evitar la falta de estabilidad y la coyunturalidad inherentes a este tipo de reglamentos y la inseguridad respecto a la vigencia de las leyes y demás normas autonómicas que produce la repercusión en aquéllas de la aprobación de Órdenes Ministeriales por parte del Estado fundadas en competencias de naturaleza básica. No obstante, lo cierto es que las reticencias de las sentencias anteriores al uso de Órdenes Ministeriales para regular las bases de la planificación general de la actividad económica no han llegado a consolidarse como doctrina en la jurisprudencia y que, por el contrario, han sido muchas las sentencias que han admitido Órdenes Ministeriales bajo el manto de esta competencia. Incluso, como caso extremo, hay que señalar la STC 133/1997, FFJJ 17 y 18, que atribuye carácter básicos a unas circulares de la Comisión Nacional del Mercado de Valores. Más aún, en la STC 197/1996, FJ 4.c) se llega a justificar la remisión al reglamento de la decisión sobre modificación o eliminación del régimen de distancias mínimas entre instalaciones dedicadas a la distribución de gases licuados del petróleo con el paradójico argumento de que tal decisión es parte de "un proceso dirigido a la liberalización del sector cuya culminación exige adoptar diversas acciones unitarias... con incidencia en la planificación económica general y en la específica de este sector energético». Esto es tanto como invertir la regla general sentada por la STC 69/1988, al afirmar que, precisamente porque se trata de una decisión básica para la planificación económica, debe ser adoptada mediante reglamento.

Todo lo anterior se explica, en buena parte, por el hecho de que el Tribunal Constitucional haya admitido en el ámbito de esta competencia la regulación de subvenciones y otras medidas de apoyo al ejercicio de 
las actividades económicas, así como el establecimiento de medidas destinadas a dar respuestas a situaciones de marcado carácter coyuntural que afectan a todas o a algunas actividades económicas en el conjunto del Estado o en una parte de él, ya que estos tipos de medidas encuentran en la Orden Ministerial el instrumento más adecuado para acometer su regulación. De esta manera, la interpretación extensa del ámbito material de la regulación básica que se admite en el marco de esta competencia ha tenido como consecuencia, también, el abandono, en la práctica, de los requisitos formales de la regulación de las bases que se habían establecido en las sentencias que en mayor medida han contribuido a precisar el concepto del término "bases", entre las que destaca la ya citada STC 69/1988.

La que se acaba de examinar no es la única desviación que se registra en el ámbito de la competencia sobre bases y coordinación de la planificación general de la actividad económica en cuanto a la utilización de las fuentes del derecho que sería esperable de las previsiones constitucionales y de los pronunciamientos constitucionales que han detallado los requisitos formales que, a priorihabría de observar la ordenación de las bases. Además, hay que señalar que, mientras el artículo 131 de la Constitución se refiere sólo a los "proyectos" de planificación "del Gobierno", que, tal como se deriva de la jurisprudencia constitucional sobre los requisitos formales de las bases, habrían de ser aprobados por las Cortes mediante ley, se ha empleado en la realidad una práctica según la cual el Congreso de los Diputados aprueba un dictamen sobre la situación de un sector de la actividad económica entre cuyas conclusiones se recoge la conveniencia de hacer un plan para la mejora de las condiciones de ejercicio de dicha actividad y el Gobierno se encarga de aprobar dicho plan y las Órdenes Ministeriales que establecen las subvenciones con las que se pretende apoyar la aplicación de aquél, lo que ha sido admitido con el argumento de que «en puridad, las bases se contienen en las Órdenes que aplican los Planes aprobados por el Gobierno" (STC 242/1999, FJ 9). En este último caso, la jurisprudencia ha entendido que las Órdenes Ministeriales quedan suficientemente cubiertas por la escueta intervención parlamentaria mediante la que se aprueba la cláusula que contiene la autorización al Gobierno para elaborar el plan.

A todo ello hay que añadir que no son infrecuentes los casos en los que el Tribunal Constitucional ha admitido también actos de naturaleza ejecutiva como ejemplo de bases de la planificación general de la actividad económica, como mencionaremos a continuación más detalladamente. 


\section{LOS ARGUMENTOS PARA LA INTERPRETACIÓN DEL CONTENIDO MATERIAL DE LAS BASES Y DE LA COORDINACIÓN DE LA PLANIFICACIÓN GENERAL DE LA ACTIVIDAD ECONÓMICA}

Una de las claves para entender la jurisprudencia del Tribunal Constitucional acerca del contenido de la competencia sobre bases y coordinación de la planificación general de la actividad económica reside en que aquél no ha interpretado el ámbito de las bases en esta materia como "común denominador normativo dirigido a asegurar, de manera unitaria y en condiciones de igualdad, los intereses generales a partir del cual pueda cada Comunidad Autónoma, en defensa de sus propios intereses, introducir las peculiaridades que estime convenientes y oportunas, dentro del marco competencial que en la materia le asigne su Estatuto" (STC 69/1988, FJ 5) . Por el contrario, para el Tribunal Constitucional las bases de la planificación general de la actividad económica consisten, según formulación de la STC 95/1986, FJ 4, ampliamente aceptada por la jurisprudencia, en el establecimiento de "las normas estatales que fijen las líneas directrices y los criterios globales de ordenación de sectores económicos concretos, así como las previsiones de acciones o medidas singulares que sean necesarias para alcanzar los fines propuestos dentro de la ordenación de cada sector ${ }^{8}$ ".

Como se ve, el Tribunal Constitucional ha interpretado la competencia del Estado para establecer las bases de la planificación general de la actividad económica en un sentido directivo, esto es, como directrices, criterios globales de ordenación y acciones o medidas destinadas a lograr los fines propuestos, lo cual requiere indagar cuáles son los objetivos a los cuales deben ir encaminadas las normas y actuaciones del Estado que pretendan ampararse en esta competencia. Dichos objetivos son, principalmente, garantizar el mantenimiento de la unidad de mercado (SSTC 118/1996, FJ 10, y 208/1999, FJ 6) y de la «unicidad (sic) del orden económico nacional» (STC 1/1982, FJ 1), de la "unidad del sistema económico general» (STC 133/1997, FJ 4), o de la "unidad económica» (SSTC 152/1988, FJ 2, 186/1988, FJ 2, 96/1990, FJ 3, y 146/1992, FJ 2), si bien también se ha interpretado la extensión de la competencia sobre las bases de la planificación general de la actividad económica desde la perspectiva de "las líneas de actuación tendentes a alcanzar los objetivos de la política

8 Sobre las distintas formas de interpretar el concepto de bases, vid ALBERTí ROVIRA, E.; "La noción de "bases" y el desarrollo estatutario", en Estudios sobre el Estatuto de Autonom a del Pa s Vastcb, ob. cit., págs. 311 y ss. 
económica general o sectorial» (STC 96/1990, FJ 3, y, en el mismo sentido, SSTC 80/1985, FJ 1, y 188/1989, FJ 5, además de algunas de las anteriores), o bien desde la incidencia de las medidas en principios rectores de la política económica y social (SSTC 95/2002, FFJJ 7 y 11, seguida por las SSTC 190/2002, 228/2003 y 230/2003). De esta manera, el Tribunal Constitucional viene encuadrando en esta competencia todas las normas y actuaciones, sean cuales sean su naturaleza, contenido y grado de detalle, que identifique como dirigidas a garantizar tales objetivos. Así, el Tribunal Constitucional ha admitido como básicas para la planificación de la actividad económica normas que exceden el contenido que, en abstracto, podría deducirse del concepto de "bases", tales como:

a) Normas de detallpor ejemplo, la STC 133/1997, FJ 4, relativa a la Ley 24/1988, del Mercado de Valores, ha reconocido que la posibilidad de que las bases comprendan «regulaciones detalladas de aspectos concretos de las materias o que, incluso, incluyan la potestad de realizar actos de ejecución... tiene su fundamento no sólo en las exigencias de la unidad del sistema económico general, para cuya preservación no bastan los denominadores comunes de naturaleza normativa, sino también en la necesidad de actuaciones singulares directas por razones de urgencia para prevenir naturales perjuicios irreversibles al interés general».

b) Leyes medidalas sentencias 95/1986 y 152/1988 han interpretado como leyes medida la normativa reguladora de medidas de fomento y apoyo al ejercicio de actividades económicas concretas. Se trata en estos casos de un tipo específico de "acciones y medidas singulares" dirigidas a categorías determinadas de destinatarios que se agotan en su primera aplicación y que están encaminadas a apoyar el logro de determinados fines de la ordenación de cada sector de la actividad económica mediante la concesión de subvenciones y préstamos con tipo de interés subsidiado a sus beneficiarios. En este sentido, la STC 95/1986, tras señalar que las bases de la planificación general de la actividad económica deben ser entendidas como las directrices, criterios globales y acciones o medidas singulares encaminados al logro de los fines propuestos para la ordenación de cada sector de la actividad, indica en su fundamento jurídico cuarto, recogiendo las aportaciones hechas previamente por la STC 179/1985, que «no es metodológicamente adecuada y puede resultar artificiosa e inútil toda distinción entre lo básico y lo no básico si pretende aplicarse a "los preceptos integrantes de una medida que sólo puede ser considerada y aplicada como unidad", en el bien entendido, claro 
es, de que "sólo pueden ser considerados como elementos de la medida aquellos preceptos directa o indirectamente ordenados a la obtención del fin propuesto", de tal manera que, "si la disposición que la contiene incluyese otros no relacionados con esa finalidad, respecto de ellos la delimitación competencial apoyada en la distinción entre normas básicas y normas de desarrollo habrá de ser respetada» (STC 179/1985)". Ello ocurre cuando, como en el caso examinado en la sentencia, la regulación se refiere a "elementos indisociables de cada medida, o (que), dicho de otro modo, son instrumentos necesarios para conseguir los fines de interés público que con ellas se persiguen ${ }^{9}$." De este modo, la sentencia atribuyó al Estado el conjunto de la regulación de las ayudas a jóvenes agricultores que examinaba.

En casos como los decididos por estas sentencias, el Tribunal Constitucional ha hecho una interpretación material mediante la que ha reconocido al Estado no la facultad para regular en un grado básico los aspectos más importantes de una determinada actuación, sino para regular por completo aquellos aspectos considerados como básicos por su importancia para la actuación sobre una materia e, incluso, a veces, para realizar los actos de carácter ejecutivo relativos a la regulación básica.

c) Actuaciones coyunturales y singulłarsd.C 1/1982, aunque admite en su fundamento jurídico primero que normalmente las bases «deben tener estabilidad, pues con ellas se atiende a aspectos más estructurales que coyunturales", señala también que existen sectores económicos, como es el caso de la ordenación del crédito, en los que "la consecución de aquellos intereses generales perseguidos por la regulación estatal (...) exigirá que, atendiendo a circunstancias coyunturales y a objetivos de política monetaria y financiera, el Gobierno de la Nación proceda a la concreción e incluso a la cuantificación de medidas contenidas en la

9 Sigue la misma línea de las sentencias indicadas la STC 188/1989, FJ 5, y la STC 197/1996, FJ 4.b). Vid.s,obre la STC 179/1985, ALBERTí ROVIRA, E.; "Leyes medida y distribución de competencias: un paso más en la interpretación extensiva de las «bases normativas" en la jurisprudencia constitucional. (Comentario a la sentencia del Tribunal Constitucional 179/1985, de 19 de diciembre)», REDC, 18 (1986), 141 y ss., PEÑUELAS I REXACH, L.; "Facultad de gasto del Gobierno central, actividad de fomento y bases de la planificación de la actividad económica», REDF , 72 (1991), 527 y ss., y RECASENS CALVO, J.; "Los límites constitucionales de la actividad estatal de fomento en sectores económi- 
regulación básica del crédito». En igual sentido se pronuncia la STC 57/1983, FJ 7, sobre la atribución al Estado de la decisión sobre las autorizaciones a las Entidades Locales para acordar el recurso al crédito por en cima de un tope fijado (STC 57/1983, FJ 7), y la STC 91/1984, FJ 5, que examina una Orden Ministerial relativa a unos préstamos a damnificados por inundaciones para incluirlos en el porcentaje o coeficiente que las Cajas de Ahorro deben invertir obligatoriamente sobre los recursos ajenos depositados en ellas.

Otros ejemplos se encuentran en la STC 188/1989, FJ 5, que acepta la regulación mediante reglamento de una medidas de fomento del cultivo del maíz, al señalar que ello es aceptable cuando una disposición "regula unas medidas de intervención económica de naturaleza coyuntural mediante las cuales es manifiesto que no se pretende definir de manera estable la línea divisoria de las competencias estatales y autonómicas en materia de agricultura sino sólo subvenir a necesidades concretas y perentorias en cumplimiento de los objetivos de la política económica general para cuya garantía se han consignado con anterioridad los fondos presupuestarios correspondientes", y en la STC 223/2000, FJ 6, relativa a la regulación de la actividad de almacenamiento, suministro y distribución de gases licuados del petróleo, que señala que "“la intervención del Reglamento en la delimitación de lo básico" se justifica por "el carácter marcadamente técnico o por la naturaleza cambiante y coyuntural de la materia que es objeto de la misma -SSTC 76/1983, 77/1985 y 86/1989" (STC 147/1991, FJ 4)».

d) Actos de ejecucicomo ejemplo puede señalarse, además de la STC 133/1997, ya citada, la 208/1996, FJ 6, para la cual "parece, pues, innecesario destacar el carácter básico que, desde la competencia estatal ex artículo 149.1.13a , reviste en cuanto a la defensa de la competencia se refiere, pues nos hallamos ante un elemento definitorio del mercado. De modo que no sólo la normación, sino todas las actividades ejecutivas que determinen la configuración real del mercado único de ámbito nacional habrán de atribuirse al Estado".

Así pues, frente a la tendencia de derivar el contenido de las bases del concepto que supone esta categoría jurídica, se ha impuesto otra que interpreta el contenido de las bases en función de conceptos como los de unidad económica y de unidad de mercado, de los objetivos de la política económica nacional y de los principios rectores de la política social y eco- 
nómica, ajenos a la regla del propio artículo 149.1.13a de la Constitución, de lo cual se ha derivado una extensión del ámbito de las bases hasta abarcar todas las actuaciones que el Tribunal Constitucional ha entendido encaminadas a lograr dichos objetivos ${ }^{10}$. Esto, asimismo, reviste la interpretación del concepto de bases de un alto grado de casuismo, ya que el grado de detalle y concreción admisible en las normas y actuaciones del Estado desde esta competencia depende de la medida en que se valore la repercusión de cada una de tales normas y actuaciones en el logro de la unidad de mercado, de la unidad económica, de los objetivos de la política económica nacional o de los principios rectores de la política social y económica $y$, asimismo, del grado de uniformidad de la normativa y de las actuaciones que se juzgue necesario en cada materia para salvaguardar tales objetivos.

Como se ve, con este modelo de interpretación los conceptos de unidad de mercado y de unidad económica quedan convertidos en la verdadera fuente de la competencia del Estado, en una línea que permite al Estado establecer cuantas normas y actuaciones considere necesarias para garantizar en la práctica tales nociones, convertidas en objetivos de la acción del Estado por encima del tenor de las reglas de reparto de competencias entre el Estado y las Comunidades Autónomas. Es en este sentido como debe entenderse que, en la práctica, el contenido de la competencia sobre bases y coordinación de la planificación general de la actividad económica venga siendo identificado en la jurisprudencia del Tribunal

${ }^{10}$ Con ello, estos conceptos adquieren una función distinta de la que debe reconocérseles habitualmente con arreglo a un planteamiento objetivo del significado y el sentido con los que los utiliza la Constitución, de la cual se deduce que los principios de unidad del orden económico (derivado del principio de unidad del artículo $2^{\circ}$ ) y de unidad de mercado (como fórmula que sintetiza los principios de libertad de circulación y establecimiento del artículo 139.2) deben ser considerados como un límite que han de respetar tanto el Estado como las Comunidades Autónomas en el ejercicio de las competencias concretas que la Constitución y los Estatutos les atribuyen, que el interés respectivo del Estado y de las Comunidades Autónomas debe entenderse valorado ya por la Constitución y los Estatutos de Autonomía a la hora de repartir entre el Estado y las Comunidades Autónomas las competencias que delimitan el ámbito de poder que corresponde a cada una de dichas instancias, que la dirección de la política interior (dentro de la que debe encuadrarse la política económica) es una función que el Gobierno debe ejercer en el marco delimitado por las competencias atribuidas por la Constitución al Estado y que los principios de la política económica y social son objetivos que deben ser perseguidos por el Estado y las Comunidades Autónomas mediante el ejercicio de sus respectivas competencias.

Vid. sobre los principios de unidad económica y de unidad de mercado, las obras 
Constitucional con el de "ordenación de la actuación económica general», de "ordenación general de la economía", de "dirección general de la economía" u otros contenidos similares (SSTC 1/1982, 95/1986, 152/1988, 177/1990, 225/1993, 29/1994, 128/1999, 95/2001, entre otras). Muchas de las sentencias indicadas siguen la estela de la STC 29/1986, donde la ordenación de la actuación económica general quedó preconstituida como competencia de titularidad estatal que sería posible ejercer "cuando para conseguir objetivos de la política económica nacional, se precise una acción unitaria en el conjunto del territorio del Estado, por la necesidad de asegurar un tratamiento uniforme de determinados problemas económicos o por la estrecha independencia de actuaciones a realizar en distintas partes del territorio nacional», lo que, según la misma sentencia, permitiría al Estado efectuar una planificación de detalle ${ }^{11}$.

Sin embargo, este modelo de interpretación encierra una tautología, ya que toda norma y actuación del Estado sobre la actividad económica, por definición, irá encaminada a aumentar el grado de unidad económica en el conjunto del Estado o al logro de los objetivos de la política económica estatal. La necesidad de admitir un espacio para que las Comunidades Autónomas puedan actuar también en relación con las actividades económicas ha obligado al Tribunal Constitucional a establecer unos criterios, por vía interpretativa, con los que distinguir qué casos pueden ser encuadrados en la competencia del artículo 149.1.13 Constitución y qué otros casos, por el contrario, rebasan el ámbito de dicha regla competencial y deben considerarse como propios del ámbito de las competencias de las Comunidades Autónomas en relación con la ordenación de las actividades económicas. Los principales criterios señalados por la jurisprudencia a estos efectos son:

a) La incidencia en el desarrollo de la actividad econ-mica gene ral así, corresponde al Estado establecer las disposiciones normativas y llevar a cabo las actuaciones que pudieran tener una incidencia importante en el desarrollo de la actividad económica

${ }^{11}$ Sobre esta sentencia, vid.GARCÍA TORRES, J.; "La "ordenación general de la economía", título sustantivo de competencia estatal", REDC, 17 (1986), 241 y ss.; MALARET I GARCÍA, E.; $R$ gimen jur dico-administrativo de la reconversi $n$ industrial, Civitas, Madrid, 1991, "Algunas consideraciones en torno a la sentencia del Tribunal Constitucional 29/1986, de 20 de febrero", RAP, 111 (1986), 275 y ss.; y TORNOS I MAS, J. y MALARET I GARCÍA, E.; "La política de reconversión industrial. El proceso de elaboración de la Ley 27/1984, de 26 de julio, de Reconversión y Reindustrialización», en 
general en el territorio estatal. Por ejemplo, la STC 152/1988, FJ 2, encuadra en el artículo 149.1.13 la regulación de unas subvenciones a viviendas de protección oficial, al considerar "la incidencia que el impulso de la construcción tiene como factor del desarrollo económico y, en especial, generador de empleo", la STC 197/1996, FJ 17.B), enmarca en la regla competencial del mismo artículo la autorización del Estado para la actividad de distribución al por mayor de productos petrolíferos, debido, entre otras cosas, a las «importantes consecuencias para la economía nacional en su conjunto" de esta actividad (en igual sentido, la STC 223/2000, FJ 16, respecto a la regulación de las existencias mínimas de seguridad de productos petrolíferos), la STC 206/1997, FJ 9, acepta la regulación estatal del máximo de contribución anual por partícipe en los Planes de Pensiones, al considerarla "como magnitud con relevancia para la economía en general", la STC 124/2003, FJ 3, admite el establecimiento por el Estado de los criterios genéricos mínimos para el otorgamiento de licencias a grandes establecimientos comerciales, ya que, entre otras cosas "su contenido vincula la apertura de los grandes establecimientos a la incidencia que puedan tener en la actividad económica", y las SSTC 118/1996, FJ 10, 61/1997, FJ 36, y 65/1998, FJ 7, barajaron argumentos semejantes para admitir el establecimiento por el Estado de principios y previsiones normativas de carácter genérico relativos al transporte, al Patrimonio Municipal del Suelo y a las carreteras.

Por el contrario, las SSTC 125/1984, FJ 1, 197/1996, FJ 17.c), 192/1990, FJ 4, 76/1991, FJ 4, y 21/1999, FJ 5, rechazan la regulación estatal de una distinción especial de hoteles recomendados por su calidad, la autorización por el Estado para distribuidores de gases licuados del petróleo al por menor, la regulación de una campaña fitosanitaria en relación con la apicultura, determinadas actuaciones que el Estado pretendía asumir para el control de calidad de semillas y la regulación por parte del Estado de los materiales de reproducción de naturaleza forestal debido a que se trata de medidas que no poseen una «incidencia directa y significativa sobre la actividad económica general" o una "trascendencia tan fundamental en la economía».

40 En este mismo sentido se pronuncia ROCA: "de una manifestación de voluntad a favor de una confesión o solicitando una prestación que ésta ofrece, no podrá seguirse más que una presunción de pertenencia»: vid. RocA, M.J La declaraci n de la propia religi eit pág. 133. 
b) La conexi n con los objetivos de la pol tica econ mica del Estado el Estado es competente para prever las disposiciones y las actuaciones que aparezcan directamente encaminadas al logro de los objetivos de la política económica en cada sector de la actividad económica. Así, la STC 152/1988, FJ 4, admite la regulación de unas medidas del Estado para el fomento de la construcción de viviendas de protección oficial basándose en que «con ello se trata de asegurar el mantenimiento de unas inversiones fundamentales desde el punto de vista de la política económica general", la STC 63/1988, FJ 11, junto con las SSTC 96/1990, $237 / 1992,385 / 1993,171 / 1996,62 / 2001$ y 24/2002, que encuadran en la competencia sobre coordinación de la planificación la regulación por el Estado de los topes de incrementos retributivos de los empleados públicos y vinculan esta previsión al logro de determinados objetivos de política económica estatal, la STC 188/1989, FJ 5, que acepta la regulación de determinadas medidas cuya función es "sólo subvenir a necesidades concretas y perentorias en cumplimiento de los objetivos de la política económica general», o la STC 80/1985, FJ 1, que considera que el artículo 149.1.13 a de la Constitución supone "el reconocimiento a favor del Estado de la facultad para regular o incluso adoptar las medidas necesarias a fin de integrar la agricultura de la Comunidad Autónoma en la política económica general».

Lo mismo sucede cuando el Tribunal Constitucional ha entendido que determinadas actuaciones son necesarias "con el fin de conseguir los objetivos económicos... para el sector», como sucede en la STC 186/1988, FJ 7, para admitir que las autorizaciones de riego de la vid hayan de inscribirse en un Registro nacional y la atribución al Estado de la declaración de las zonas de riego de la vid en colaboración con las Comunidades Autónomas.

No obstante, el Tribunal Constitucional ha intentado también limitar los efectos de estos pronunciamientos, prueba de lo cual es la STC 171/1996, que en su fundamento jurídico tercero recopila la jurisprudencia que ha recalcado la necesidad de que las decisiones que el Estado adopte con base en el artículo 149.1.13a de la Constitución se ciñan a los "aspectos estrictamente indispensables para la consecución de los fines de política económica que aquéllas persigan (entre otras muchas, SSTC 152/1988, FJ 4, y 201/1988, FJ 2)... (o) «aquellas medidas que tengan una relación directa con los mencionados objetivos de política económica dirigidos a la consecución y mantenimiento de la estabilidad y el equilibrio económicos" (SSTC 63/1986, FJ 11, 96/1990, FJ 3, 
237/1992, FJ 4, y 68/1996, FJ 10)". De este modo, las SSTC 186/1988, FJ 6, 37/1987, FJ 7, y 115/1991, FJ 3, señalaron que determinadas actuaciones de naturaleza ejecutiva en relación con el cultivo de la vid, las normas andaluzas de reforma agraria, y la función de expedir etiquetas relativas a la calidad de semillas y plantas de vivero no alcanzan a desplegar "una eficacia incisiva en la política económica general del Estado o en los elementos básicos de la misma», ni son "una condición necesaria para alcanzar el fin propuesto de ordenación del sector.»

c) Los efectos territoriales supraauton micos de las actuaciones relativas a las actividades econ micas o la repercusi $n$ de st en intereses supraauton miAsí el Tribunal Constitucional ha abstraído en la STC 235/1999, FJ 3, diversos pronunciamientos jurisprudenciales anteriores para señalar que el ámbito de la competencia del Estado sobre las bases de la planificación general de la actividad económica engloba actuaciones de naturaleza ejecutiva ""ya lo sea porque se encuentren afectados directamente intereses supraautonómicos, o porque se trate de decisiones y actuaciones que trascienden del caso particular y de las situaciones concretas afectadas dada la interdependencia de éstas en todo el territorio nacional o, en fin, cuando el acto de ejecución comporte, por necesidad intrínseca de la materia, márgenes tan amplios de discrecionalidad que sólo pueda ser adoptado por instancias que no tengan a su cuidado intereses particulares distintos a los puramente generales" [en este sentido, SSTC 87/1993, FJ 5; 155/1993, FJ 6; 204/1993, FJ 5; 37/1997, FJ 5; y 133/1997, FJ 4.B)]». Este argumento es el que sirve de base para atraer al ámbito competencial del Estado la delimitación de los tipos de materiales de base destinados a la producción de materiales de reproducción forestal, de las regiones de procedencia de aquéllos y de los requisitos para su admisión (STC 21/1999, FJ 5), actuaciones ejecutivas de un plan sobre ordenación y mejora de explotaciones agrarias y ganaderas (STC 145/1989, FJ 6), el establecimiento de una reserva nacional compuesta por un porcentaje de los derechos de prima y cantidades de referencia asignados por la Comunidad Europea a España en relación con ciertos productos ganaderos y la adjudicación a sus beneficiarios de tales derechos y cantidades (SSTC 29/1994, FJ 3, y 45/2001, FJ 9), la reserva al Estado de actuaciones ejecutivas en relación con ayudas a la instalación de empresas turísticas en mercados exteriores (STC 242/1999, FJ 16), la facultad de autorizar a ciertos suministradores 
para la venta subvencionada de mantequilla a instituciones y colectividades sin ánimo de lucro cuando aquéllos operen en todo el territorio nacional (STC 117/1992, FJ 3) y actuaciones ejecutivas en materia de defensa de la libre competencia (STC 208/1999, FJ 6). La aplicación de este criterio se intensifica cuando las actuaciones responden al objetivo de corregir desequilibrios en el territorio del Estado (como en la STC 146/1992, FJ 1, relativa a unos incentivos regionales para la corrección de desequilibrios territoriales) o cuando se estima que la realización de determinadas actuaciones por el Estado puede dar lugar a desequilibrios territoriales (STC 186/1987, FJ 7). El mismo argumento está detrás de la atribución al Estado de la facultad para llevar a cabo la ejecución de los planes de reconversión industrial y reindustrialización en la STC 29/1986, FJ 4.

No obstante, el propio Tribunal Constitucional ha sido consciente del efecto limitativo de las competencias autonómicas que este criterio tiene y ha intentado contener su aplicación. Así, la STC 197/1996, FJ 17.A) ha señalado que el hecho de que una actividad económica se desarrolle en un ámbito supracomunitario no puede ser determinante por sí solo para encuadrar en la competencia del Estado la facultad para llevar a cabo las actuaciones encaminadas a la disciplina de aquélla, sino que para ello las actuaciones públicas sobre dichas actividades "han de ser indispensables para preservar lo básico o constituir complemento necesario para garantizar la consecución de la finalidad objetiva a que responde la competencia estatal en materia de ordenación general de la economía." Las SSTC 175/1999, FJ 6, y 190/2000, FJ 10, han complementado este pronunciamiento, al señalar que, además, para que se produzca el traslado de una actuación al ámbito competencial del Estado, es necesario que "la actividad pública que sobre él se ejerza no sea susceptible de fraccionamiento y aun en este caso, dicha actuación no pueda llevarse a cabo mediante mecanismos de cooperación y coordinación, sino que requiera un grado de homogeneidad que sólo pueda garantizar su atribución a un solo titular, que forzosamente deba ser el Estado, o cuando sea necesario para recurrir a un ente con capacidad de integrar intereses contrapuestos de varias Comunidades Autónomas (STC 243/1994, FJ 6)". De este modo, el Tribunal Constitucional ha indicado en algunas sentencias la necesidad de que el Estado acuda a mecanismos de cooperación y coordinación, o bien de que establezca los criterios de conexión territorial que permitan distinguir qué Comunidad Autónoma es la compe- 
tente para llevar a cabo actuaciones de repercusión supraautonómica, siempre que tales medios permitan que dichas actuaciones se lleven a cabo con eficacia y sin los riesgos que pudiera conllevar la disgregación de la acción de los poderes públicos (SSTC 175/1999, FJ 6, 242/1999, FFJJ 17 y 18, 190/2000, FJ 10, 223/2000, FJ 8). En el caso de la STC 208/1999, FJ 6, en relación con las medidas para la corrección de las prácticas restrictivas de la competencia otras ocasiones, la llamada a la regulación de los criterios de conexión territorial ha tenido como objeto mover al Estado a establecer los criterios para determinar cuándo una actuación corresponde al mismo Estado, debido a los efectos supraautonómicos del fenómeno a cuyo tratamiento va dirigida, y cuándo corresponde a las Comunidades Autónomas, por no tener dichos fenómenos repercusión territorial supraautonómica ${ }^{12}$.

d) La repercusi $n$ internacional de las medidas relativas a la act vidad econ mices un factor que juega también en beneficio del reconocimiento al Estado de la facultad de prever aquéllas, especialmente cuando se pretende con ellas la integración de España en el ámbito económico de la Unión Europea. Es lo que ocurre en las SSTC 29/1986, FJ 4, sobre los planes de reconversión y reindustrialización, 133/1997, FJ 9, sobre la regulación de los Mercados de Valores, 225/193, FJ 3.D), sobre horarios comerciales, y 197/1996, FJ 4.c), en relación con la distribución de productos petrolíferos.

e) La jurisprudencia ha querido compensar la tendencia expansiva de lo básico en esta materia señalando como límite a la actuación del Estado desde la competencia del artículo 149.1.13a de la Constitución el principio de no vaciamiento de las competencias de las Comunidades Aut nomaße esta forma, la regulación del Estado a partir de su competencia sobre las bases de la planificación general de la actividad económica no podría extenderse en

12 Sobre la STC 208/1999, vid. ARZOZ SANTISTEBAN, X.; "Comunidades Autónomas, puntos de conexión y defensa de la competencia", RVAP, 64 (2002), 11 y ss.; BIGLINO CAMPOS, P.; "Principio de competencia, inconstitucionalidad y nulidad a la luz de la STC 208/1999, sobre la Ley 16/1989 de Defensa de la Competencia", REDC, 59 (2000), 303 y ss.; y MAGIDE HERRERO, M.; "El reparto competencial en materia de defensa de la competencia. Perspectivas abiertas tras la STC 208/1999", RArAP, 17 
un grado tal que llegara a vaciar las competencias de las Comunidades Autónomas, normalmente reconocidas en sus Estatutos de Autonomía con el carácter de exclusivas, sobre las actividades económicas en las cuales incidiera la normativa estatal. No obstante, el Tribunal Constitucional no ha aclarado si el criterio de no vaciamiento de las competencias autonómicas se refiere a la necesidad de que las normas del Estado salvaguarden la facultad de las Comunidades Autónomas para poder regular ámbitos materiales completos y coherentes poniendo en práctica opciones políticas propias (a esta solución apunta la STC 75/1989, FJ 5), o bien si aquel principio puede considerarse salvaguardado sólo con que las normas del Estado permitan que las Comunidades Autónomas puedan regular algunos aspectos de las actividades económicas o llevar a cabo algunas actuaciones concretas, aunque se trate de aspectos y actuaciones aislados, que no permitan poner en práctica una opción coherente de ordenación de las actividades económicas (por ejemplo, en la STC 95/2001, FJ 2). Incluso, la STC 29/1986 admite que el Estado Ileve a cabo una planificación de detalle y asuma la ejecución, en cooperación con las Comunidades Autónomas, de los planes de reconversión industrial y reindustrialización, y la STC 225/1993 admite la previsión por el Estado de una medida como la que permite la liberalización de los horarios comerciales, que «no requiere ulteriores desarrollos legislativos del régimen establecido, al igual que tampoco precisa de intervenciones administrativas", pese a haber recogido antes el mismo criterio de no vaciamiento de las competencias autonómicas.

El principal inconveniente de los criterios interpretativos anteriores consiste en que introducen al Tribunal Constitucional en un subjetivismo y en un casuismo que merman en gran modo la previsibilidad de las decisiones del órgano jurisdiccional y aportan una gran inseguridad acerca del alcance y los límites de las competencias del Estado y de las Comunidades Autónomas para la ordenación de las actividades económicas. En efecto, este tipo de razonamiento hace difícil extraer conclusiones que vayan más allá del supuesto resuelto en cada ocasión y que pudieran ser generalizables a otros supuestos.

Asimismo, hay que añadir otros dos criterios que han sido utilizados para admitir la realización por parte del Estado de determinadas actuaciones sobre las actividades económicas desde su competencia acerca de las bases de la planificación general de las actividades económicas. El primero de aquéllos consiste en admitir que el Estado Ileve a cabo una regulación extensa de determinadas actuaciones considerando que ello no impi- 
de a las Comunidades Autónomas prever medidas complementarias de idéntica naturaleza sobre la misma actividad o poner en práctica actuaciones idénticas en relación con la misma normativa, con lo que ha abierto la puerta a una concurrencia o duplicidad de actuaddehesstado y de las Comunidades Autónomas) sobre ámbitos materiales coincidentes desde competencias distintas (la del Estado sobre las bases de la planificación general de la actividad económica y las competencias de las Comunidades Autónomas sobre sectores específicos de la actividad económica) ${ }^{13}$, como ocurre en las SSTC 144/1985, FJ 3, y 45/1991, FJ 3, que aceptaron una detallada regulación estatal de las medidas aplicables a actividades en zonas de alta montaña debido a que la normativa estatal permitía que las Comunidades Autónomas establecieran, con independencia del regulado en la ley estatal, sus propios regímenes de tratamiento especial de las zonas de montaña en virtud de sus competencias sobre promoción, fomento y planificación del desarrollo económico (en la misma línea, muy frecuente, en especial, en lo que toca al establecimiento de medidas de fomento de las actividades económicas, pueden citarse, entre otras, las SSTC 96/1986, FJ 3, 186/1988, FJ 7, si bien las SSTC 14/1989, FJ 3, y $64 / 1990$, FFJJ 4 y 5 , resaltan la necesidad de que las medidas dispuestas por las Comunidades Autónomas sean "complementarias, concurrentes o neutras" $y$, por lo tanto, no entorpezcan el logro de los fines a los que se dirigen las medidas establecidas por el Estado), y en la STC 29/1986, FFJJ 5 y 6.d), que admite que la Ley $27 / 1984$, de 26 de julio, de Reconversión y Reindustrialización, prevea duplicar envíos de información, que habrían de remitirse tanto a la Administración del Estado como a la Administración autonómica, e incluso autorizaciones administrativas de instalación y ampliación de industrias y actuaciones de inspección para comprobar el grado de cumplimiento de los objetivos del plan y la exactitud de los datos suministrados por las empresas, que podrían ser llevadas a cabo por ambas Administraciones (en la misma línea, por ejemplo, la STC 223/2000, FJ 19).

El segundo de los criterios aludidos reside en atraer al ámbito competencial del Estado la realización de determinadas actuaciones de naturaleza ejecutiva con el argumento de que son actuaciones instrumentales, esto es, que deben considerarse como instrumento para la aplicación de

13 VIVER I PI-SUNYER, C.; Materias competenciales y Tribunal ConstitArielonal, Barcelona, 1988, págs. 60 y ss., y, en el mismo sentido, CARRILLO, M.; "La noción de "materia" y el reparto competencial en la jurisprudencia del Tribunal Constitucional», RVAP, 36 (1993), 113. 
las normas consideradas como básicas para la planificación de las actividades económicas. Así, la STC 197/1996, FFJJ 19.b) y 21, considera las medidas ejecutivas de inspección, control y sanción relativas al régimen de existencias mínimas de seguridad entre distribuidores de gases licuados como «medidas de supervisión y control indispensables para preservar lo básico" y las atribuye al Estado, y el mismo concepto mantienen las SSTC 96/1996, FJ 26, 133/1997, FJ 12.a), y 206/1997, FJ 15, respecto a actuaciones de sanción, supervisión, inspección y vigilancia en relación con la regulación de las instituciones de crédito, los mercados de valores y las entidades de seguros. En el mismo sentido instrumental pueden citarse, entre otros, los pronunciamientos de las SSTC 186/1988, FJ 17, 86/1989, FJ 13, 197/1996, FJ 12, y 223/2000, FJ 10, relativas a la creación de Registros estatales y a la inscripción en ellos de determinados datos, y la STC 79/1992, FJ 5, que ha considerado el pago de las subvenciones como un simple acto instrumental, que debe corresponder a la Administración que tenga atribuida la resolución de los expedientes de solicitud de las ayudas.

La tendencia a la expansión del ámbito competencial del Estado en relación con la ordenación de la actividad económica ha tenido un ejemplo destacado en la regulación de las medidas de fomentole las actividades económicas, esto es, las subvenciones y otras medidas destinadas, por una parte, a apoyar desde el Estado el ejercicio de las actividades económicas, y, por otra parte, a dirigir la actividad económica de los particulares a los objetivos considerados como preferentes por la política económica del propio Estado ${ }^{14}$. Ciertamente, el punto de partida en esta materia es la sentencia 13/1992, que, sobre la base de lo dispuesto en las SSTC 179/1985

14 Vid.FERNÁNDEZ FARRERES, G.; La subvenci $n$. Concepto y $r$ gimen jur dico, Instituto de Estudios Fiscales, Madrid, 1983, "La ordenación de los sectores económicos, el poder de gasto del Estado y de las Comunidades Autónomas», en AA. VV.; El funCi⿱一土㇒ namiento del Estado Auton micMinisterio de Administraciones Públicas, Madrid, 1999, págs. 163 y ss., y La subvención y el reparto de competencias entre el Estado y las Comunidades Autónomas", REDC, 38 (1993), 225 y ss.; MEDINA GUERRERO, M.; La

incidencia del sistema de financiaci $n$ en el ejercicio de las competencias de las Comunidades Aut nomas,CEC, Madrid, 1992, págs. 491 y ss., "La incidencia del poder de gasto estatal en el ejercicio de las competencias autonómicas", REDC, 30 (1990), 65 y ss., y "Supremacía financiera, distorsión del orden competencial y cooperación en el Estado autonómico: algunas consideraciones sobre la STC 13/1992", REDC, 35 (1992), 155 y ss.; PEÑUELAS I REXACH, L.; cit., 521 y ss.; RAMALLO MASSANET, J.; "El poder de gasto del Estado: subvenciones y orden competencial", Documentaci $n$ Administrativa,32-233 (1993), 403 y ss.; RECASENS CALVO, J.; cit., 85 y ss.; y SÁNCHEZ MORÓN, M.; Subvenciones del Estado y Comunidades Aut nợemos, 
y 145/1989, establece que el poder de gasto en manos del Estado no es un título competencial autónomo que permita a aquél establecer, regular y ejecutar cualesquiera ayudas sobre cualesquiera materias, sino que aquél sólo podrá establecer ayudas "en los casos en que, por razón de la materia sobre la que opera dicho gasto o subvención, la Constitución o, en su caso, los Estatutos de Autonomía hayan reservado al Estado la titularidad de tales competencias sobre la materia subvencionada" (STC 13/1992, FJ 4 , citando las SSTC 95/1986 y 96/1990, FJ 15) y sólo podrá determinar la regulación de dichas ayudas y actuar a la hora de aplicar tales ayudas en la medida en que se lo permitan los títulos competenciales que legitimen su intervención sobre las actividades económicas a las que afecten tales ayudas, ya que "la subvención no es un concepto que delimite competencias (STC 39/1982 y 179/1985) ni el solo hecho de financiar puede erigirse en núcleo que atraiga hacia sí toda competencia sobre los variados aspectos a que pueda dar lugar la actividad de financiación (SSTC 39/1982, 144/1985, 179/1985 y 146/1986)", puesto que la persecución del interés general que representa el Estado "se ha de materializar "a través de", no "a pesar de" los sistemas de reparto de competencias articulado en la Constitución (STC 146/1986, FJ 4)» (STC 13/1992, FJ 4, y, en el mismo sentido, la STC 152/1988, FJ 3, entre otras).

Ahora bien, la aplicación de esta doctrina general al ámbito de las actividades económicas ha generado una patente intensificación de la intervención del Estado sobre dichas actividades, que ha seguido las siguientes líneas:

a) Por una parte, el Estado ha encontrado en el título competencial relativo a las bases y la coordinación de la planificación general de la actividad económica el fundamento para establecer y regular medidas de fomento, estableciendo el destino de las partidas presupuestarias correspondientes, de cualesquiera actividades económicas sobre las cuales las Comunidades Autónomas sean, a su vez, titulares de competencias consideradas por sus Estatutos de Autonomía como exclusivas, o como exclusivas en el marco de la ordenación general de la actividad económica. Las SSTC 201/1988, FJ 3, y 13/1992, FJ 8, admiten este efecto, si bien exigen que, en tal caso, se territorialicen los fondos destinados por el Estado a dotar las medidas de fomento para su gestión por parte de las Comunidades Autónomas ${ }^{15}$

${ }^{15}$ Con ello, se rectifica la línea, en sentido contrario, que habían sostenido las SSTC $96 / 1986$ y $88 / 1987$. 
De esta manera, el Estado dispone de un medio que le permite dirigir y ordenar de una manera muy intensa el ejercicio de las actividades económicas. Baste considerar en qué grado dependen actividades económicas como la agricultura, la ganadería, la industria o el turismo de las subvenciones y otras ayudas públicas previstas para ordenar el desarrollo de las mismas. Se trata, en todos estos casos, de actividades sobre las que, sin embargo, las Comunidades Autónomas han asumido en sus Estatutos de Autonomía competencias exclusivas o exclusivas en el marco de la ordenación general de la actividad económica.

b) Por otra parte, el Estado ha encontrado en dicho título competencial la base para llevar a cabo la regulación de todos los elementos fundamentales de dichas medidas de fomento. El Tribunal Constitucional, de este modo, ha admitido que el Estado regule los beneficiarios de las medidas de fomento y los requisitos o condiciones que deban cumplir para poder acogerse a las ayudas, la definición de las actividades a las que se destine la subvención y de los objetos sobre los que deban ejercerse tales actividades para tener derecho a percibir aquélla, los fines de las medidas de fomento, el tipo concreto de ayudas en el que consistan tales medidas (principalmente, subvenciones y préstamos con tipo de interés subsidiado), el nivel de protección que ofrezcan dichas medidas a quienes ejerzan las actividades o actuaciones que las motiven, el montante de los recursos destinados a la financiación de las medidas y la fuente de estos recursos (lo que incluye la previsión de un posible complemento de aportación privada), el importe máximo que puedan recibir quienes se acojan a las medidas de fomento y los elementos y reglas que deban tenerse en cuenta para el cálculo de la cuantía de las ayudas, los tipos de interés que hayan de abonar los beneficiarios de préstamos en condiciones especiales, plazos de amortización y garantías exigibles a aquéllos y el momento de concesión de las ayudas, entre otros aspectos (entre otras, pueden verse las SSTC 95/1986, 152/1988, 75/1989, 145/1989, 79/1992, 128/1999 y 175/2003). De esta manera, la regulación de las medidas de fomento de las actividades económicas por parte del Estado, desde la competencia sobre las bases de la planificación general de la actividad económica, ha alcanzado una extensión tal que, prácticamente, agota las posibilidades de ordenación jurídica de dichas medidas en cuanto a los aspectos que realmente definen la naturaleza y los objetivos de aquéllas. Aunque el Tribunal Constitucional ha señalado que las Comunidades Autónomas pueden, en ejercicio de 
sus competencias sobre las actividades económicas, complementar la regulación del Estado acerca de dichas medidas, el grado de predeterminación por parte del Estado de la ordenación jurídica de aquéllas hace difícil encontrar de qué manera podrían las Comunidades Autónomas complementar la regulación estatal en los aspectos ya ordenados por la propia normativa del Estado. Ciertamente, en algún caso el Tribunal Constitucional ha considerado que la regulación por parte del Estado de algunos de los elementos de determinadas medidas de fomento superaba la extensión que puede admitirse desde una competencia que sólo alcanza a las bases y coordinación de la planificación general de la actividad económica (por ejemplo, las SSTC 242/1999, FFJJ 10 y 12, y 190/2000, FJ 10), pero, en general, como se ha señalado, la regulación por parte del Estado de dichas medidas, prácticamente, agota las posibilidades de ordenación jurídica de los aspectos sustanciales de las medidas.

La cuestión, en realidad, no está tanto en el detalle de las previsiones estatales, sino en la acumulación de elementos a las que aquéllas se refieren, que da como resultado una predeterminación completa de la regulación de aquéllas. En este marco, queda a las Comunidades Autónomas únicamente la regulación de algunos aspectos de carácter procedimental o técnico, o bien la ejecución de la regulación de las medidas, salvo los casos excepcionales en los que también el Estado puede asumir actuaciones ejecutivas a tal fin. Así, según ha sintetizado la STC 175/2003, corresponde a las Comunidades Autónomas la regulación de las solicitudes y de la subsanación y mejora de la solicitud, el estudio y evaluación de las solicitudes, la propuesta y aceptación de las subvenciones, la concesión de la subvención, determinar el plazo de resolución de los procedimientos, determinar el órgano competente para resolver las solicitudes, el pago de las subvenciones concedidas, el pago anticipado de subvenciones, controlar la justificación de la realización del proyecto y la realización de los gastos previstos en el mismo y establecer órganos de asesoramiento y de seguimiento de la ejecución de los proyectos.

c) Incluso, en determinadas ocasiones, el Tribunal Constitucional ha permitido que el Estado asuma la ejecución de algunas actuaciones encaminadas a la aplicación de la regulación de las subvenciones y ayudas relativas a actividades económicas en las que las Comunidades Autónomas tienen reconocidas competencias calificadas en sus Estatutos de Autonomía como exclusivas. Así, el Tribunal Constitucional ha admitido esta práctica al considerar 
que pueden encuadrarse en la competencia sobre las bases y la coordinación de la planificación general de la actividad económica actuaciones ejecutivas de medidas de fomento de la actividad económica cuando resulte imprescindible para asegurar la plena efectividad de las medidas dentro de la ordenación básica del sector al que se refieran, garantizar las mismas posibilidades de obtención y disfrute de dichos incentivos por parte de sus potenciales destinatarios en todo el territorio nacional y evitar que se sobrepase la cuantía global de los fondos estatales o de los créditos que hayan de destinarse al sector [SSTC 95/1986, FJ 5, y 13/1992, FJ 8.d)]. En tales supuestos, la jurisprudencia ha admitido que el Estado se reserve la ejecución de actuaciones tales como la adjudicación de las subvenciones o beneficios en los que consistan las medidas (STC 152/1988, FJ 5, 29/1994, FJ 3, y 45/2001, FJ 9), la formalización de convenios con entidades financieras (SSTC 95/1986, FJ 5, y 152/1988, FJ 5), el pago de las ayudas (STC 79/1992, FJ 5) y otras actuaciones que se centralizan en virtud de la dimensión supracomunitaria de las ayudas (STC 145/1989, FJ 6).

Junto a esta línea, sin embargo, destacan otras sentencias en las que la posibilidad de que el Estado asuma la ejecución de actuaciones relativas a las medidas de fomento debe limitarse a los casos en los que los riesgos que se originarían si tales actuaciones fueran asumidas por las Comunidades Autónomas no pudieran evitarse estableciendo criterios objetivos concretados mediante una adecuada planificación, criterios de conexión territorial o mecanismos de cooperación y coordinación (SSTC 186/1999, FJ 10, y 242/1999, FJ 17).

d) La predeterminación de la regulación de las medidas destinadas a apoyar y ordenar el ejercicio de las actividades económicas que les viene dada a las Comunidades Autónomas alcanza su mayor grado en el caso de las subvenciones establecidas por la Unión Europea. En tales casos, la Unión Europea establece las subvenciones relativas a determinadas actividades económicas (fundamentalmente, la agricultura y la ganadería) y regula los elementos fundamentales de dichas subvenciones, pero el Estado, automáticamente, emplea su competencia sobre las bases de la planificación general de la actividad económica para entrar a precisar y complementar la regulación proveniente de las instituciones europeas, de tal manera que el legislador autonómico queda convertido en un legislador supletorio en segundo grado, que sólo puede llenar los huecos que haya dejado la normativa europea y 
la estatal. Habitualmente, la regulación de tales subvenciones llega a las Comunidades Autónomas con un grado de determinación tal, después de la intervención de la Unión Europea y del Estado, que aquéllas no pueden hacer más que dedicarse a la ejecución de dicha normativa. El resultado de todo ello contrasta fuertemente con la doctrina de la sentencia 79/1992 según la cual la integración de España en la Unión Europea no altera el reparto de competencias establecido entre el Estado y las Comunidades Autónomas, de manera que el desarrollo y la ejecución de la normativa europea debe corresponder, bien al primero, bien a las segundas, dependiendo de cuáles sean las materias a las que se extiendan sus respectivas competencias y las actuaciones que puedan llevar a cabo en dichas materias a partir de los títulos competenciales que hayan asumido sobre ellas ${ }^{16}$.

\section{EL EFECTO DE LA INTERPRETACIÓN DE LA COMPETENCIA DEL ARTÍCULO 149.1.13a DE LA CONSTITUCIÓN SOBRE LAS COMPETENCIAS DE LAS COMUNIDADES AUTÓNOMAS RELATIVAS A LOS DISTINTOS SECTORES DE LA ACTIVIDAD ECONÓMICA. LA COMPETENCIA} DEL ESTADO SOBRE LA COORDINACIÓN DE LA PLANIFICACIÓN GENERAL DE LA ACTIVIDAD ECONÓMICA

Se ha hecho un lugar común en la doctrina afirmar que las competencias asumidas formalmente como exclusivas por las Comunidades Autónomas en sus Estatutos de Autonomía deben considerarse, en realidad, como competencias compartidas, ya que aquéllas se ven obligadas a respetar las normas y actuaciones llevadas a cabo por el Estado en ejercicio de otras competencias, sobre todo las llamadas horizontales o trans-

\footnotetext{
${ }^{16}$ No obstante, ya la misma sentencia, en su fundamento jurídico tercero, admitió que el Estado estableciera algunas normas destinadas a facilitar la ejecución de los reglamentos comunitarios con carácter supletorio "con el fin de asegurar que los posibles beneficiarios de las medidas no se vean perjudicados por la pasividad de las Comunidades Autónomas al desarrollar la regulación comunitaria de aquéllas y de garantizar el cumplimiento del derecho comunitario derivado" e, incluso, que asumiera la ejecución de las medidas en los casos en que las instituciones europeas asignen a España una cantidad máxima global para todo el territorio del Estado, "ante la eventualidad de que las solicitudes sobrepasen la cuantía máxima global asignada a España» (STC 79/1992, FJ 4).
} 
versales, que les permiten intervenir en distintos grados sobre los mismos ámbitos materiales objeto de competencias autonómicas. Este fenómeno, como se ha podido comprobar, se da de manera paradigmática en relación con las competencias de las Comunidades Autónomas sobre las actividades económicas por efecto de la influencia en la ordenación de las mismas de la competencia del Estado sobre las bases y la coordinación de la planificación general de la actividad económica. Pero, además, la forma de aplicar e interpretar esta competencia ha dado lugar a situaciones que se acercan al modelo alemán de competencias concurrentes. En efecto, como hemos visto, en algunas ocasiones el Tribunal Constitucional ha admitido prácticas con las que el Estado, desde su competencia del artículo 149.1.13a de la Constitución, llega a agotar la ordenación posible de determinados aspectos relativos al ejercicio de las actividades económicas e, incluso, asume la realización de actuaciones de carácter ejecutivo. Ello provoca que, en tales casos, quede a disposición del Estado decidir sobre la extensión de su actuación en torno a tales aspectos, incluyendo la opción de agotar las posibilidades de actuación pública sobre ellos, y que, paralelamente, el ámbito dispuesto para que las Comunidades Autónomas ejerzan sus competencias sea mayor o menor dependiendo de la extensión de la normativa estatal y de las actuaciones cuyo ejercicio asuma el Estado.

Junto a todo ello, hay que señalar otro criterio interpretativo que ha sido ampliamente utilizado por el Tribunal Constitucional y que provoca también una corrección en la naturaleza teórica de las competencias de las Comunidades Autónomas. Se trata del criterio según el cual corresponde al Estado determinar la regulación de todos los aspectos tras los cuales exista una decisión por una opción política determinada y llevar a cabo también las actuaciones de carácter ejecutivo que impliquen una opción política [STC 178/1992, FJ 2, 87/1993, FJ 5, 155/1993, FJ 6, 204/1993, FJ 6, 37/1997, FJ 5, y 133/1997, FJ 4.B)]. En correspondencia, quedaría a las Comunidades Autónomas, pues, la ejecución de actos de carácter procedimental, técnico o reglado, o, como mucho, la precisión de la regulación del Estado en detalles que puedan considerarse como mero desarrollo técnico o procedimental de las normas estatales y que no comporten la adopción de una decisión política previa. Es patente, sin embargo, que este criterio choca con la concepción general acerca de la naturaleza de la autonomía de las Comunidades Autónomas, que comporta la facultad de adoptar libremente las decisiones de naturaleza política necesarias para el ejercicio de sus competencias legislativas y ejecutivas.

Los efectos anteriores han sido, si cabe, ampliados como consecuencia de la interpretación de la otra función que atribuye el artículo 149.1.I3 de la Constitución al Estado sobre la planificación general de la actividad económica, esto es, la coordinación. El Tribunal Constitucional ha 
rechazado una interpretación formal de la coordinación que encontraba en ella sólo la previsión de una facultad del Estado para establecer procedimientos mediante los que el Estado y las Comunidades Autónomas pudieran ejercer sus competencias de forma coordinada y ha optado por un concepto material de lo que significa la coordinación, a partir del cual ha admitido que el Estado atraiga a su espacio competencial la realización de actuaciones normalmente ejecutivas (SSTC 144/1985, FJ 4, 13/1988, FJ 2, 128/1999, FJ 7, 98/2001, FJ 8, entre otras muchas), aunque en algunos casos también de carácter normativo (por ejemplo, en la STC 63/1986 y las que siguen su estela, ya citadas, sobre el establecimiento de los topes retributivos de los empleados públicos, o en las SSTC 183/1988, FJ 7, 96/1990, FJ 11, y 237/1992, FJ 8, sobre la exigencia a las Comunidades Autónomas de la realización de unos programas de desarrollo regional siguiendo una metodología común), cuando se ha considerado que concurren circunstancias que harían que determinadas actuaciones públicas pudieran perder eficacia u obstaculizar el logro de objetivos de la política económica nacional si fueran realizadas por las Comunidades Autónomas de forma disgregada ${ }^{17}$. De acuerdo con la STC 144/1985, FJ 4, que sistematiza pronuncia-

17 Sobre los distintas interpretaciones del concepto de coordinación y sus diferencias con otros conceptos cercanos, como los de colaboración o cooperación, vid. ALBERTÍ ROVIRA, E.; Federaci n y cooperaci n en la Rep blica Federal CECemana, Madrid, 1986, "La coordinación entre el Estado y las Comunidades Autónomas", Documentaci n Administratiz30-231 (1992), 49 y ss., y "Las relaciones de colaboración entre el Estado y las Comunidades Autónomas", REDC, 14 (1985), 135 y ss.; CRUZ VILLALÓN, P.; "La doctrina constitucional sobre el principio de cooperación", en AA. VV. (coord. J. Cano Bueso); Comunidades Aut nomas e instrumentos de cooperaci n interterritoPálamento de Andalucía, Tecnos, Sevilla, 1990, págs. 119 y ss.; GUILLÓ SÁNCHEZ-GALIANO, A. y CÓRDOBA CASTROVERDE, D.; "Principios de coordinación de la Jurisprudencia constitucional", Documentaci n Administrati230-231 (1992), 337 y ss.; MARCOS FERNÁNDEZ, A. de; "Jurisprudencia constitucional sobre el principio de cooperación", Documentaci n Administrativa40 (1994), 265 y ss.; MENÉNDEZ REXACH, A.; "La cooperación, ¿un concepto jurídico?", Documentaci n Administrativa, 240 (1994), 11 y ss.; PÉREZ CALVO, A.; "Actuaciones de cooperación y coordinación entre el Estado y las Comunidades Autónomas", REALA, 235-236 (1987), 467 y ss.; RUIZRICO RUIZ, G. y RUIZ RUIZ, J. J.; "La cooperación y las Comunidades Autónomas: La problemática constitucional del Título Primero de la Ley 30/1992», REALA, 266 (1995), 387 y ss.; SÁNCHEZ MORÓN, M.; "La coordinación administrativa como concepto jurídico", Documentaci n Administrati230-231 (1992), 11 y ss.; SANTOLAYA MACHET-

TI, P.; Descentralizaci n y cooperaci $n$ : introducci $n$ al estudio de los mecanismos de cooperaci $n$ en los Estados basados en la descentralizaci n pol tica, su aplicaci $n$ caso espa ollnstituto de Estudios de la Administración Local y Autonómica, Madrid, 1984, y "En torno al principio de cooperación», RDPOI,21 (1984), 83 y ss.; y TAJADURA 
mientos que habían hecho anteriormente las SSTC 32/1983, 42/1983 y 11/1984 de forma dispersa, "la coordinación general debe ser entendida como la fijación de medios y de sistemas de relación que hagan posible la información recíproca, la homogeneidad técnica en determinados aspectos y la acción conjunta de las autoridades (...) estatales y comunitarias en el ejercicio de sus respectivas competencias de tal modo que se logre la integración de actos parciales en la globalidad del sistema». Se trata de una competencia que "persigue la integración de la diversidad de las partes o subsistemas en el conjunto o sistema, evitando contradicciones o reduciendo disfunciones que, de subsistir, impedirían o dificultarían, respectivamente, la realidad misma del sistema». Para ello, "la integración de la diversidad de las partes en un conjunto unitario, perseguida por la actividad de coordinación (...), exige la adopción de las medidas necesarias y suficientes para lograr tal integración».

No obstante, en los últimos años el Tribunal Constitucional viene señalando que el recurso a la competencia sobre coordinación, entendida de tal modo, debe considerarse como un remedio subsidiario, que sólo puede ser utilizado cuando se han probado otros medios para evitar los riesgos de la actuación de las Comunidades Autónomas y éstos no han dado resultados. Por ello, el Tribunal Constitucional viene obligando al Estado a acudir a instrumentos alternativos, tales como el establecimiento de criterios objetivos de planificación, de criterios de conexión territorial y de mecanismos de colaboración e información recíproca entre las Administraciones públicas implicadas (SSTC 80/1985, FJ 2, 79/1992, FJ 5, 106/1987, FJ 4, 186/1999, FJ 10, y 208/1999, FJ 6), con carácter preferente a asumir la realización de actuaciones integrantes del ámbito teórico de las competencias autonómicas desde su competencia para la coordinación de la planificación de la actividad económica, así entendida.

\section{CONCLUSIONES Y PROPUESTAS}

Las reflexiones anteriores ponen de manifiesto que la interpretación amplia de la competencia del Estado sobre las bases y la coordinación de la planificación general de la actividad económica ha puesto a disposición del Estado un vasto arsenal de argumentos mediante los cuales justificar la atracción a su espacio competencial de la facultad para dictar normas o llevar a cabo actuaciones sobre actividades económicas acerca de las cuales las Comunidades Autónomas tienen atribuidas competencias enunciadas como exclusivas en sus Estatutos de Autonomía. Ello ha dado lugar a una práctica en la que el Estado ha llevado a cabo una intensa actividad normativa, salpicada de ocasiones en las que también ha asumido la reali- 
zación de actuaciones de carácter ejecutivo, encaminada a la ordenación de las actividades económicas sobre las cuales las Comunidades Autónomas han asumido competencias formalmente exclusivas y, paralelamente, a una reducción del ámbito en el que las Comunidades Autónomas pueden ejercer sus competencias sobre dichas actividades, que se manifiesta tanto en el campo cuantitativo, dado que son muchos los aspectos de las actividades económicas objeto de competencias de las Comunidades Autónomas que éstas se encuentran regulados por el Estado, como en el campo cualitativo, puesto que esta práctica ha provocado una reducción drástica del ámbito de autonomía política de las Comunidades Autónomas a la hora de ordenar las actividades económicas, ya que aquéllas encuentran predeterminadas por el Estado, en ocasiones con un alto grado de detalle, todas las líneas de actuación sobre dichas actividades.

Para corregir esta situación sería necesario, por un lado, que el Tribunal Constitucional hiciera un esfuerzo por limitar la extensión que hoy en día admite a la actuación del Estado sobre las actividades económicas a partir del artículo 149.1.13a de la Constitución. La manera más adecuada de hacer esto consiste en una reinterpretación de la competencia sobre bases y coordinación de la planificación general de la actividad económica a través de una vuelta al significado objetivo de los términos en los que viene expresada. Así, sería necesario ceñir las actuaciones realizadas por el Estado a través de esta competencia a aquéllas que incidan directamente en actividades de producción y prestación de servicios en el mercado, es decir, en actividades económicas, y no en otros elementos que, teniendo repercusión en tales actividades, son tratados en competencias sectoriales específicas y distintas del propio Estado y de las Comunidades Autónomas. Además, el encuadramiento de determinadas actuaciones en esta competencia habría de limitarse a aquéllas que, por su trascendencia para el desarrollo de las actividades económicas, por su planteamiento genérico de todos los aspectos y cuestiones que presenten dichas actividades y por su vocación de dirigir el ejercicio de tales actividades a determinados fines, puedan calificarse como manifestación de la actuación de planificación. Finalmente, sería conveniente recuperar la noción original de las bases como normas de rango preferentemente legal encaminadas a dotar la regulación de determinadas materias de un mínimo común de homogeneidad en todo el territorio del Estado a partir del cual las Comunidades Autónomas pudieran llevar a cabo con amplitud sus propias regulaciones de tales materias aplicando para ello políticas propias, con el fin de, por un lado, limitar la extensión de lo que hoy en día se viene considerando como básico para la planificación de las actividades económicas, y, por otro lado, exigir que, salvo casos excepcionales y justificados 
(por ejemplo, la regulación de las medidas de fomento y ayuda a las actividades económicas, que por su propia naturaleza debe ser encauzada a través de normas reglamentarias), las normas básicas vengan articuladas mediante ley. Junto a ello, cabe destacar la necesidad de seguir insistiendo en que la facultad de coordinación, entendida en sentido material, como ocurre hoy en día, debe ser considerada como último recurso cuando a través de ella el Estado pretende atribuirse la facultad de ejercer actuaciones que corresponden a las Comunidades Autónomas, y en que, por lo tanto, se debe acudir preferentemente a técnicas de cooperación entre ambas instancias y al establecimiento de los correspondientes criterios de conexión territorial para solventar los posibles problemas que pudiera plantear a la eficacia de las actuaciones públicas el hecho de que se disgreguen como consecuencia de su ejercicio por parte de las Comunidades Autónomas.

Como segundo punto, es necesario volver a insistir en la necesidad de articular cauces para la participación de las Comunidades en la tarea normativa del Estado cuando ésta afecta a materias en las que aquéllas han asumido competencias que en sus Estatutos de Autonomía les vienen reconocidas con la condición de exclusivas. Ciertamente, lo ideal sería que esta participación se hiciera a través del Senado, pero es notorio que éste dista de funcionar hoy en día como auténtica Cámara de representación territorial de las Comunidades Autónomas en el ejercicio de la función legislativa del Estado. Sin embargo, el artículo 131.2 de la Constitución establece una vía de participación de las Comunidades Autónomas en el proceso de planificación de la actividad económica que resulta interesante a estos efectos. Esta vía hasta ahora no ha sido empleada a causa de una interpretación del Tribunal Constitucional según la cual sólo resultaría exigida en los casos en los que el Gobierno pretenda elaborar una planificación global del conjunto de la actividad económica (STC 29/1986, FJ 3, 186/1988, FJ 7, 227/1988, FJ 20, 103/1989, FJ 5, y 45/1991, FJ 4, entre otras). Pero sería posible interpretar este artículo en el sentido de que la participación de las Comunidades Autónomas que establece resultaría necesaria para la elaboración de todas las normas que el Estado dote de carácter planificador en uso de su competencia del artículo 149.1.13a de la Constitución cuando afecten a actividades económicas sobre las que las Comunidades Autónomas tengan atribuidas competencias formalmente exclusivas.

De este modo, tomando como base el artículo 131.2 de la Constitución sería posible entender que la confluencia sobre un ámbito material de la competencia del Estado para la definición de las bases y la coordinación de la planificación general de la actividad económica y las competencias exclusivas de las Comunidades Autónomas sobre sectores concretos de dicha actividad debería dar lugar, no a un repliegue de las 
competencias autonómicas en proporción al espacio material y funcional ocupado por el Estado a partir de la suya, sino a reconocer un supuesto de concurrencia de las facultades del Estado y de las Comunidades Autónomas en el tramo material y funcional susceptible de ser comprendido dentro de las bases de la planificación de cada sector de la actividad económica, lo que obligaría a instaurar mecanismos que aseguraran la participación y promovieran el acuerdo entre ambas instancias políticoterritoriales en la elaboración y aprobación de los proyectos de leyes y, en su caso, normas reglamentarias que concreten a nivel normativo las bases y la coordinación de la planificación general de la actividad económica, de cara a permitir que las Comunidades Autónomas pudieran aportar en él su parecer y sus propuestas acerca de dichos proyectos ${ }^{18}$. Precisamente, las Conferencias Sectoriales relativas a cada sector de la actividad económica constituyen el órgano en el que podría llevarse a cabo dicha participación autonómica en la elaboración de las normas estatales relativas a las bases de la planificación de la actividad económica, si bien tales Conferencias deberían ser reforzadas para que cumplieran realmente su función de órgano para la coordinación y el acuerdo en relación con esta materia. Incluso, se podría pensar en instituir una Conferencia de Planificación de la Actividad Económica en la que se centralizara el debate y la aprobación de todos los proyectos de ley que pretendieran ampararse en la competencia sobre planificación del artículo 149.1.13를 de la Constitución.

18 Vid. sobre este tema, ALBERTí ROVIRA, E.; "La planificación conjunta en el federalismo cooperativo", en Constituci n y econom aob..c,it., págs. 25 y ss. 